\title{
Research on the Contents and Structure \\ of Social Support for Private Entrepreneurs
}

\author{
Xueyan Wei \\ School of Education \\ Jiangnan University \\ Wuxi 214122, China \\ E-mail: d05weixueyan@zju.edu.cn \\ Chongming Wang \\ College of Management \\ Zhejiang University \\ Hangzhou 310058, China
}

\begin{abstract}
Firstly, this paper holds a semi-structural interview to 19 private entrepreneurs in different industries from different areas. Secondly, this paper analyzes the contents of the interview records and designs a questionnaire to survey the social support for private entrepreneurs based on literatures and interviews. Finally, this paper makes statistical analysis of 143 forecasting data and 289 effective measurement data. The research reveals the four-factor structural mode of social support. Here, the four factors are emotion support, information support, instrument support, and feedback support.
\end{abstract}

Keywords: New venture creation, Social support, Entrepreneur

\section{Introduction}

What are the characteristics of the social support for entrepreneurs on earth? Nan Lin (1986) and other scholars advance the integrated definition of social support, which aggregates different scholars' views. According to this integrated definition, social support refers to the apperceived or practical instrument or expressive resources supplied by communities, social network, and close partners. House (1981) offers the operational definition of social support. In his opinion, social support includes individual apperceived important instrument or expressive resources supplied by others and network structure, namely (1) emotion and concern; (2) instrument support; (3) information support; (4) praise or feedback support. (1) Emotion support is the most important social support, including sympathy, concern, love, and trust (House, 1981). Especially, it can be realized by an operational definition, such as offering self-respect, friendship, trust, concern, and hearing. (2) Instrument support includes activities that help to satisfy individual needs, such as offering work help, service, and capitals, paying for checks, etc. (3) Information support means supplying an individual with information that can help to manage internal or external problems. (4) Feedback support is also a kind of information flow. It comes from individuals and can be used to evaluate others. It includes feedbacks from others, such as managers and individuals performances. Although these four supports are not completely independent, they display an independent dimension of social support respectively (House, 1981). Based on these definitions, House develops a questionnaire to survey these social supports. This paper adopts House's dimensions.

In China, it needs to be further analyzed and discussed which measurement is better for analyzing the structural characteristics of social support network for entrepreneurs and whether it is necessary to make a double check under Chinese cultural background. In addition, the dimension of social support obtained by the entrepreneur group must be modified and verified. Therefore, this paper adopts the structural equation modeling and other high statistical analysis 
methods study the dimensional structure of social support for entrepreneurs in an empirical research, hoping to supplying theoretical basis and practical guidance for researches on new venture creation.

\section{Research method}

\subsection{Semi-structural interview and questionnaire design}

Firstly, based on the semi-structural interview to 19 private entrepreneurs and the conclusions of Wang (2001) and House (1981), this paper focuses on four dimensions of social support, including information support, emotion support, instrument support, and feedback support. Then, the questionnaire is designed by interviewing private entrepreneurs with different backgrounds and taking references from literatures related with new venture creation. Finally, according to the questionnaire, the subjects of the research are mainly private enterprises in four industries (computer industry, manufacturing and processing industry, service industry, and construction industry) in Beijing, Shanghai, Hangzhou, Wenzhou, Ningbo, Quzhou, Xuzhou, Nanjing, Wuxi, and Changchun. By means of testing, we further examine the quality of questionnaire in representation, differentiation, simplification, and exactness. Then, we accept five experts' suggestions and complete the final formal questionnaire by amending the initial questionnaire and deleting some questions. The questionnaire adopts Likert Scale, from one to five respectively standing for full non-accordance to full accordance.

\subsection{Samples and data collection}

The first group of samples is questionnaires filled out by 143 private entrepreneurs (including the vice presidents and the enterprisers who hold more than $10 \%$ of stocks. This paper takes them as effective samples). Researchers provide 240 questionnaires and 160 samples are returned. The return ratio is $66.7 \%$. Delete 17 ineffective samples. The effective samples are 143 . The ratio of effective return is $59.6 \%$. The collected data will be used for a probing factor analysis of social support for entrepreneurs. The second group of samples consists of questionnaires filled out by 289 private entrepreneurs. Researchers provide 357 questionnaires and 310 samples are returned. The return ratio is $86.8 \%$. Delete 21 ineffective questionnaires. The effective questionnaires are 289 . The ratio effective return is $80.9 \%$. The collected data will used for a testing factor analysis of social support for entrepreneurs. In the aspect of responders' conditions, male $(81.8 \%)$ and female (18.2\%); educated in junior middle school and elementary school or below (12.8\%), high school (25.6\%), junior college (33.6\%), college and master or above (28\%); in the aspect of enterprise background, manufacturing and processing industry (39.2\%), computer software industry (24.6\%), construction industry (13.1\%), service industry (25.3\%); in the aspect of stage of new venture, foundation stage (32.2\%), growing stage (40.5\%), mature stage (20.4\%), transition stage (6.9\%); in the aspect of enterprise size, large (1.4\%), partial large (3.8\%), medium (31.3\%), partial small (30.8\%), and small (32.9\%).

\subsection{Statistical analysis}

This paper adopts SPSS13.0 and structural equation modeling software AMOS4.0 to make data analysis. The statistical analysis methods include probing factor analysis and testing factor analysis.

\section{Research result}

\subsection{Probing factor analysis}

By item variation and sample testing, the efficiency of samples and the test of sphericity indicate that we can adopt factor analysis for samples and items in this research (Bartlett's test of sphericity: Approx. Chi-Square $=1415.220, \mathrm{df}=$ $\left.210 ; \mathrm{KMO}=.739^{* * *}\right)$. The diagram shows that four factors will be the best. The probing factor analysis shows that we can refine four factors from the twenty questions of 27 items after tests. Four questions are about information support, four about emotion support, four about feedback support, and two about instrument support. All items have a factor loading larger than 30 . The scope is from .562 to .869 .

Data show that the four factors explain the connotation of social support for new venture creation to a comprehensive degree. The explainable variance variations of four factors are all between $28.24 \%$ and $16.15 \%$. In accumulation it can explain $73.39 \%$ of variation. The internal consistency coefficient is between 0.709 and 0.864 . The general internal consistency coefficient is .926 .

\subsection{Testing factor analysis}

In this research, we use the second group of samples to make testing factor analysis of social support for entrepreneurs. The model diagram and the fit index are showed in Figure 1 and Table 2. It rightly verifies the four dimensional model derived from the probing factor analysis. (1) The path coefficients between each factor and its observation index are relatively higher (0.60 above), what proves that these factors have stronger representation and abstractness. (2) The path coefficients between factors are at a medium level or above, what proves that there are certain differentiation and close association between factors. As for the fit index, except AGFI is relatively lower, others reach the significant standard. 


\section{Discussion}

By means of probing factor analysis and testing factor analysis, This research concludes the four dimensional model of social support for new venture creation, including (1) emotion support, (2) instrument support, (3) information support, and (4) feedback support.

(1) Emotion support, as one of structural dimension of social support for new venture creation, is the most import dimension. It means entrepreneurs apperceive emotional support in new venture creation, including sympathy, concern, love, and trust (House, 1981). Especially, it can be accomplished by an operational definition, including self-respect, friendship, trust, concern, and hearing. Under Chinese cultural background, people are not good at express their emotions. Entrepreneurs are always devoting themselves to "enterprises' survival and development", what may make them feel lonely in a sense. Especially during the development or mature stage, the phenomenon is more prominent. (2) Instrument support includes instrument activities that are helpful to entrepreneurs, such as offering work helps, services, funds, and paying off checks. An interesting fact is that the instrument support for Chinese private entrepreneurs mostly focuses on whether the society can provide supports for entrepreneurs' families. In enterprises, another important aspect of instrument support is whether entrepreneurs can apperceive and get practical helps. As for funds or paying off checks, entrepreneurs do not regard it as extremely important instrument support. At the very beginning of new venture creation, this kind of instrument support may be more important. But more financing is usually realized by entrepreneurs in developing enterprises. Therefore, one person's money support seems to be useless. (3) Information support means the society can provide with information about dealing with individual or environmental problems for entrepreneurs. According to items in interviews, entrepreneurs agree that information about enterprises, products, and market are more valuable. (4) Feedback support is also a kind of information flow, which is coming from people who can be used by entrepreneurs to evaluate themselves. It also includes others' feedback information, for example, comparing with other same-sized enterprises in same industries. It aims at helping entrepreneurs establish their directions and acquire better acceptance in new venture creation. Although the four kinds of support are not mutually independent completely, they display their independent dimensions of social support (House, 1981).

\section{References}

House, J.S. (1981). Work stress and social support, Reading. MA: Addison-Wesley.

Lin, N., Dumin, M.Y. \& Woefel, M. (1986). Measuring Community and network support. In N.Lin, A.Dean, \& W.Edsel(Eds.0,Social Support, Life Events and Depression. Academic Press: Orlando, pp153-170.

Wang, X.Y. (2001). Expatriate Social Support network, psychological well-being, and performance: A theoretical examination and an empirical test. Doctor dissertation.

Table 1. The factor analysis result of social support for new venture creation

\begin{tabular}{|c|c|c|c|c|}
\hline Measurement item & $\begin{array}{l}\text { Factor } \\
1\end{array}$ & $\begin{array}{l}\text { Factor } \\
2\end{array}$ & $\begin{array}{l}\text { Factor } \\
3\end{array}$ & $\begin{array}{l}\text { Factor } \\
4\end{array}$ \\
\hline $\begin{array}{l}\text { Factor 1: information support coefficient } \alpha=.843 \\
\text { - Somebody will offer important information about competitors in new } \\
\text { venture creation }\end{array}$ & .869 & -.010 & .030 & -.178 \\
\hline $\begin{array}{l}\text { - Somebody will offer important information about products in new } \\
\text { venture creation }\end{array}$ & .863 & -.065 & .085 & -.108 \\
\hline $\begin{array}{l}\text { - Somebody will offer important information about advantages and } \\
\text { disadvantages of products in new venture creation }\end{array}$ & .835 & -.150 & .048 & .159 \\
\hline $\begin{array}{l}\text { - Somebody will offer important information about products in same } \\
\text { industry in new venture creation }\end{array}$ & .686 & .200 & -.137 & .081 \\
\hline $\begin{array}{l}\text { Factor 2: feedback support coefficient } \alpha=.849 \\
\text { - Somebody will tell me what activities are not in accordance with } \\
\text { commercial principles in new venture creation }\end{array}$ & -.090 & .876 & .082 & -.092 \\
\hline - Somebody will tell me what I expect for in new venture creation & .000 & .862 & .227 & -.202 \\
\hline - Somebody will tell me what I want to do is right in new venture creation & -.018 & .720 & -.096 & .274 \\
\hline $\begin{array}{l}\text { - Somebody will give me objective feedback that helps me know how to } \\
\text { deal will problems in new venture creation }\end{array}$ & .212 & .634 & -.098 & .240 \\
\hline Factor 3: emotion support & & & & \\
\hline
\end{tabular}




\begin{tabular}{|c|c|c|c|c|}
\hline $\begin{array}{l}\text { - Somebody will concern about my happiness and healthy in new venture } \\
\text { creation }\end{array}$ & .072 & .195 & .850 & -.245 \\
\hline $\begin{array}{l}\text { - Somebody will help me when I am in trouble in new venture creation, } \\
\text { what makes me feel better }\end{array}$ & -.053 & -.211 & .832 & .082 \\
\hline $\begin{array}{l}\text { - Somebody will make me relax when I feel exhausted in new venture } \\
\text { creation }\end{array}$ & .027 & .294 & .779 & .287 \\
\hline $\begin{array}{l}\text { - Somebody will comfort me when I am frustrated in new venture } \\
\text { creation }\end{array}$ & .023 & .282 & 601 & .163 \\
\hline $\begin{array}{l}\text { Factor 4: instruction support coefficient } \alpha=.709 \\
\text { - Somebody will help me take care my family when I am busy or on } \\
\text { business }\end{array}$ & -.129 & -.057 & .052 & .863 \\
\hline - Somebody will help me out of troubles in new venture creation & .263 & .089 & .085 & .562 \\
\hline
\end{tabular}

Table 2. The testing analysis result of social support for new venture creation

\begin{tabular}{|l|l|l|l|l|l|l|l|l|l|}
\hline $\begin{array}{l}\text { Measurement } \\
\text { model }\end{array}$ & $\chi^{2}$ & df & RMSEA & GFI & AGFI & NFI & TLI & CFI & IFI \\
\hline $\begin{array}{l}\text { Independent } \\
\text { model }\end{array}$ & 663.222 & 28 & & & & & & & \\
\hline Testing model & 32.159 & 14 & 0.085 & 0.96 & 0.89 & 0.95 & 0.94 & 0.97 & 0.97 \\
\hline
\end{tabular}

RMSEA: Root Mean Square Error of Approximation; GFI: Goodness of Fit Index; AGFI: Adjusted Goodness of Fit Index; NFI: Normed Fit Index; TLI: Tucker-Lewis Index; CFI: Comparative Fit Index; IFI: Incremental Fit Index.

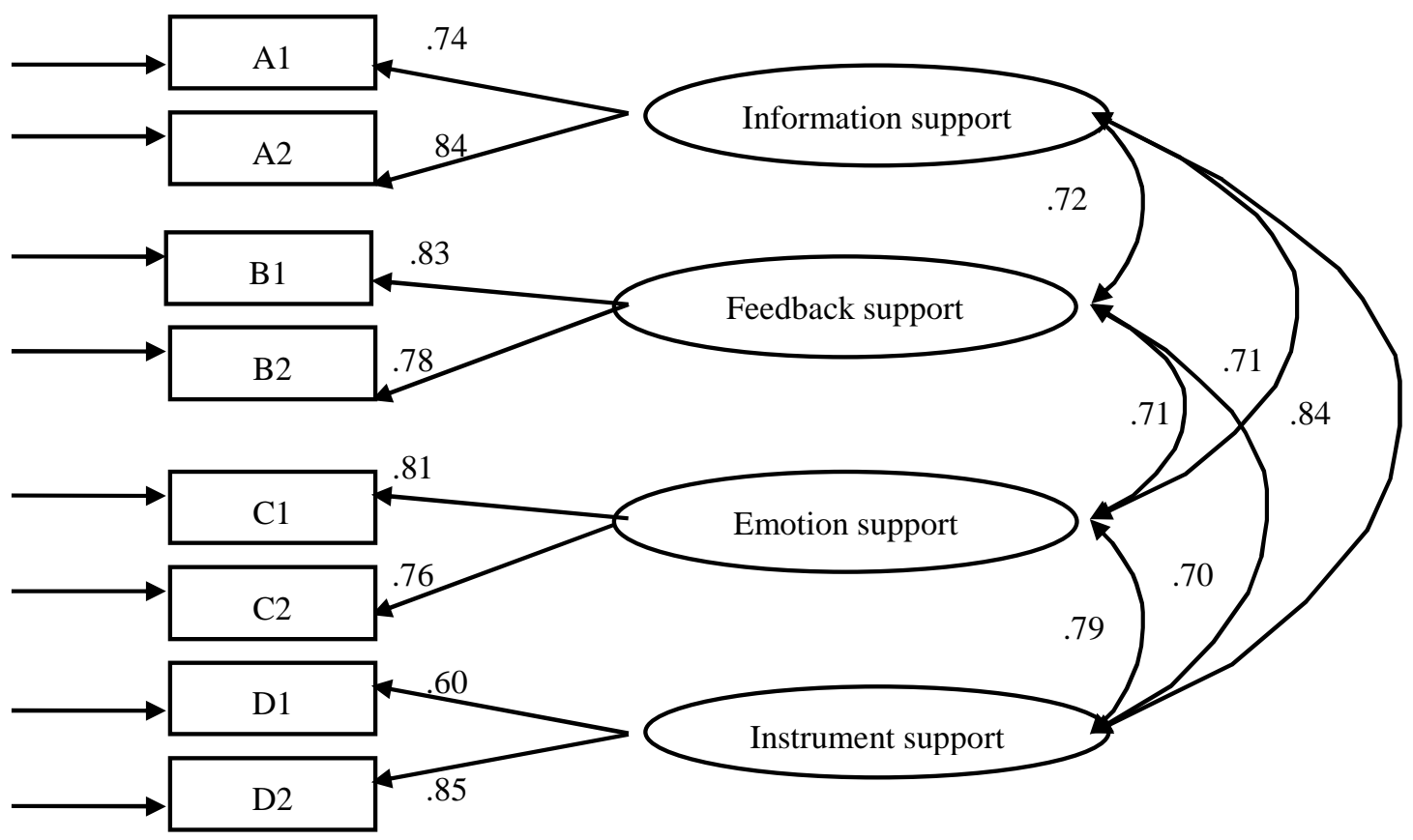

Figure 1. The Testing Factor Analysis of Social Support Structural Model 